\title{
Trisomy 18 syndrome with cleft foot
}

DAVID CASTLE AND RENEE BERNSTEIN
MRC Human Ecogenetics Research Unit, Department of Human Genetics, School of Pathology, South
African Institute for Medical Research and University of the Witwatersrand, Johannesburg, South Africa.

SUMMARY Ectrodactyly of the feet has been reported only twice in association with trisomy 18 syndrome. A severe form of this anomaly, the first with published illustrative $x$ rays, is described in a male infant with trisomy 18 syndrome. It is suggested that this may represent an extreme expression of the foot anomalies more commonly associated with this syndrome.

Since the initial descriptions of trisomy 18 (Edwards) syndrome in 1960, numerous cases have been described. The features have been reviewed by Smith $^{1}$ and by Schinzel. ${ }^{2}$ The most common limb abnormalities in trisomy 18 syndrome include the characteristically clenched hand with overlapping digits, nail hypoplasia, and the short dorsiflexed hallux. Equinovarus, rocker bottom feet, and syndactyly of the second and third toes are features in 10 to $50 \%$ of cases. ${ }^{1}$ Only two previous cases of trisomy 18 syndrome have been reported to have cleft foot. ${ }^{34}$ We present a third such case, the first in which this anomaly appears symmetrical and the first where $x$ ray evidence distinguishes it from other forms of ectrodactyly.

\section{Case report}

The infant, a black male, was born at term to a 45 year old woman, by elective caesarean section for breech presentation. Apgar scores at birth were 0 ; the child was resuscitated but survived only 10 hours.

Features suggestive of the trisomy 18 syndrome included small size (weight $1998 \mathrm{~g}$, crown-rump length $32 \mathrm{~cm}$ ), low slung ears with adherent lobuli, narrow palpebral fissures, microretrognathia, high arched palate, excessive lanugo, and the characteristic clenched hands (fig 1). In addition to these features there was a marked ectrodactyly of both feet, with a deep cleft between the hallux and the other toes, which were syndactylous. The hallux itself was severely dorsiflexed (fig 2).

Received for publication 4 August 1987

Accepted for publication 10 August 1987
$X$ rays of the feet showed a short hallux bilaterally with complete absence of the second ray on the right and hypoplasia of the third ray. On the left the second ray was markedly hypoplastic and the third ray somewhat less so. The soft tissue syndactyly was evident (fig 3).

Necropsy confirmed the external dysmorphic features and revealed a ventricular septal defect and a unilateral horseshoe kidney. No other internal abnormalities were noted.

Peripheral blood metaphases showed a modal number of 47 , karyotype $47, X Y,+18$, in all 17 cells analysed. No structural abnormality was detected on Giemsa banded metaphases.

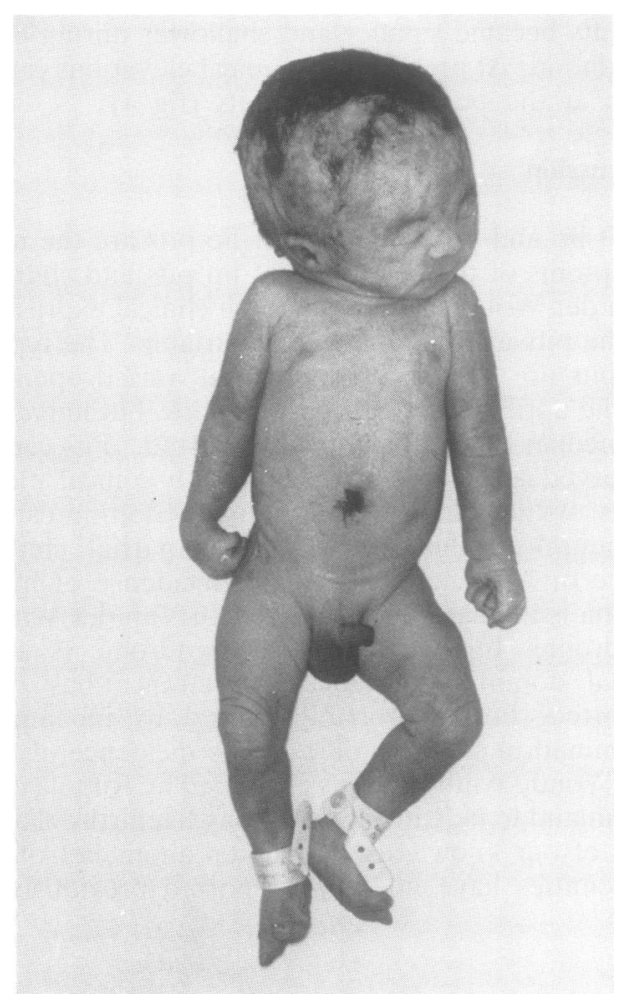

FIG 1 The infant, showing features of trisomy 18 syndrome and clefting of the foot. 

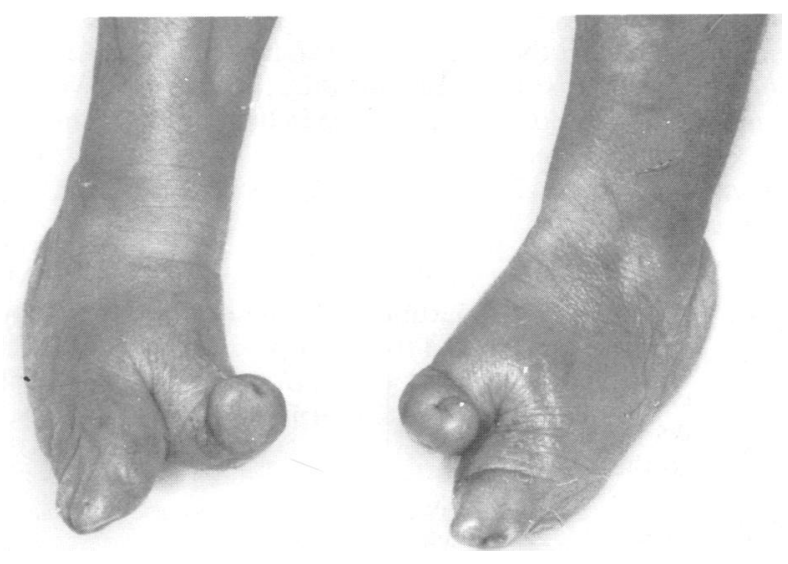

FIG 2 Close up of the feet, showing clefting between the dorsiflexed hallux and the other syndactylous toes.

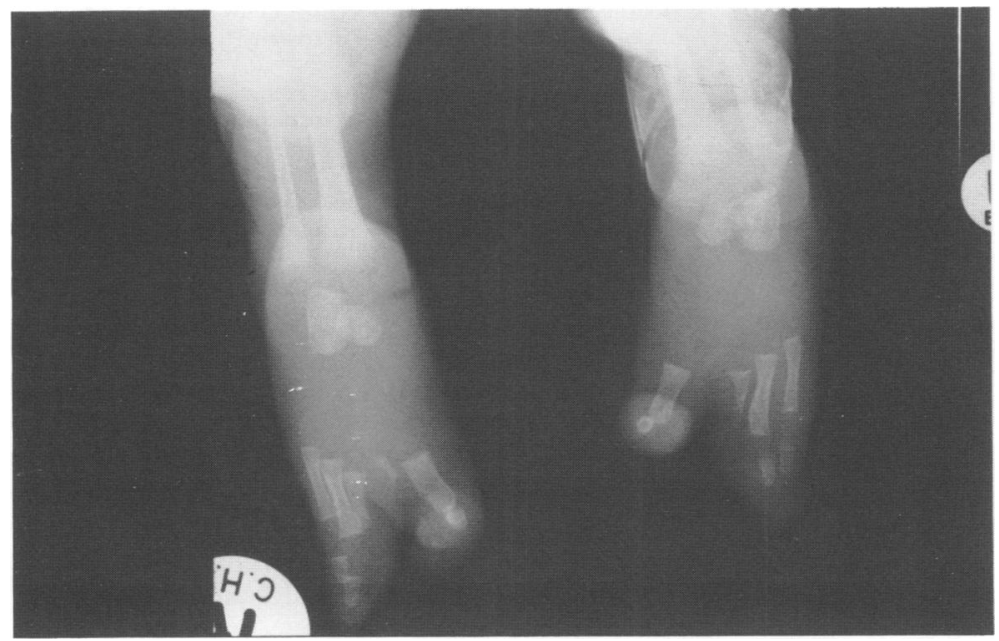

FIG $3 X$ ray appearance of the feet. Note absence of central ray with hypoplasia of the marginal rays.

\section{Discussion}

Limb abnormalities in trisomy 18 syndrome are common. Smith's review in $1982^{1}$ distinguishes those features found in more than $50 \%$ of cases, those found in 10 to $50 \%$, and those occurring in less than $10 \%$ of cases. The first category includes the typical clenched hand with overlapping index finger, nail hypoplasia, and a short dorsiflexed hallux valgus. Foot anomalies present in 10 to $50 \%$ of cases include equinovarus, rocker bottom feet, and syndactyly of the second and third toes. A gap between the hallux and the other toes is also common. ${ }^{2}$

Christianson and Nelson ${ }^{5}$ reported four cases of trisomy 18 syndrome with severe lower limb reduction anomalies, gross talipes equinovarus, and preaxial poly- or syndactyly being the commonest features. None of their cases exhibited clefts of the foot.

Ramirez-Castro and Bersu ${ }^{6}$ performed detailed necropsies on eight trisomy 18 infants to ascertain patterns of limb abnormalities and to hypothesise on their pathogenesis. Most of their attention was directed to the upper limbs where consistent anomalous patterns of muscle and tendon insertion were thought to explain partly some of the developmental anomalies; no such consistent features were found in the lower limbs.

We are aware of only two previous reports of clefting of the feet in association with trisomy 18 syndrome. In the case described by Butler et al, ${ }^{3}$ the right foot exhibited a cleft between the hallux and 
the fourth and fifth toes with absence of the other toes, and the left foot had a smaller midline cleft with absence of only the third toe. Moerman et $a l^{4}$ reported a case of trisomy 18 syndrome with a 'lobster claw' deformity of the left foot. Neither of these cases had published illustrative $x$ rays.

The present case differs from those previously reported in having a deep cleft of both feet between the hallux and the other toes, which were syndactylous. The $x$ ray (fig 3 ) confirms that the cleft is between the hallux and the other toes and shows loss of the second ray of the left foot, with hypoplasia of the third ray, and hypoplasia of both these rays on the right. As such, the deformity is analogous to the type I split hand/split foot anomaly described by Temtamy and McKusick, ${ }^{7}$ but the hypoplasia of the marginal rays makes it closer to the atypical variety of Lange.

Other chromosomal syndromes which have been associated with foot anomalies similar to those found in trisomy 18 include duplications of $9 p$, $10 \mathrm{q} 24 \longrightarrow \mathrm{qter}$, and $14 \mathrm{p}$ (syndactyly of the second and third toes), and trisomy 13 (cleft between first and second toes, syndactyly). ${ }^{1}$ A number of syndromes have occasionally exhibited clefting of the feet; these include Carpenter syndrome, De Lange syndrome, ectrodactyly-ectodermal dysplasia-clefting syndrome, Goltz syndrome, Jarcho-Levin syndrome, Miller syndrome, and Pfeiffer syndrome. ${ }^{1}$ The $x$ ray appearance of our case distinguishes it from the classical familial split hand/split foot anomaly (following autosomal dominant, recessive, or $\mathrm{X}$ linked recessive inheritance), ${ }^{78}$ as well as from the autosomal dominant split hand and split foot anomaly described among the Wadoma tribe of Eastern Zimbabwe and the Talaunda of Botswana. ${ }^{9}$

There are certain features in the present case which appear to be an exaggerated form of the foot anomalies more commonly described in trisomy 18 syndrome. A wide gap between the hallux and the other toes with a tendency to syndactyly of the latter. is frequent in the trisomy 18 syndrome, while dorsiflexion of the hallux is also a common feature. As such, our case may represent the extreme end of this maldevelopment spectrum.

We wish to thank Dr M Ossip for referring thea infant to us for investigation. Dr K A Margolius ofe the Department of Anatomical Pathology, SAIMR, performed the necropsy. DC wishes to acknowledge the support of a South African Medical Research $\vec{\omega}$ Council Post-Internship Scholarship.

\section{References}

1 Smith DW. Recognizable patterns of human malformations. Philadelphia: Saunders, 1982.

2 Schinzel A. Catalogue of unbalanced chromosome aberrations inco man. Berlin: Walter de Gruyter, 1983:628-33.

${ }^{3}$ Butler LJ, Snodgrass GJAI, France NE, Sinclair L, Russell A.o E(16-18) trisomy syndrome: analysis of 13 cases. Arch Dis Child 1965;40:600-11.

${ }^{4}$ Moerman P, Fryns JP, Goddeeris P, Lauweryns JM. Spectrum of clinical and autopsy findings in trisomy 18 syndrome. J Genex응 Hum 1982;30:17-38.

${ }^{5}$ Christianson AL, Nelson MM. Four cases of trisomy $18^{\stackrel{\oplus}{+}}$ syndrome with limb reduction malformations. J Med Genet $\overrightarrow{0}$ 1984;21:293-7.

6 Ramirez-Castro JL, Bersu ET. Anatomical analysis of ${ }^{\circ}$ developmental effects of ancuploidy in man-the 18-trisony syndrome. II. Anomalies of the upper and lower limbs. Ang Med Genet 1978;3:285-306.

7 Temtamy S, McKusick V. The genetics of hand malformations New York: Alan R Liss, 1978:36-71.

${ }^{8}$ Mufti MH, Wood SK. Ectrodactyly in sisters and half sisters. 응 $J$ Med Genet 1987;24:220-4.

9 Viljoen DL, Beighton P. The split-hand and split-foot anomaly $\overrightarrow{\bar{O}}$ in a Central African Negro population. Am J Med Genet 3 1984;19:545-52.

Correspondence and requests for reprints to Dr Renee Bernstein, Department of Human Genetics, South African Institute for Medicalọ Research, PO Box 1038, Johannesburg 2000, 욱 South Africa.

\title{
Deletion of band $5 \mathrm{q} 21$ in association with a de novo translocation involving $2 \mathrm{p}$ and $5 \mathrm{q}$
}

\author{
JAR-FEE YUNG*, NANCY WILLIAMSON†, I SALAFSKY \\ ${ }^{*}$ Department of Pediatrics, University of Illinois, Chicago; †Rockford Memorial Hospital, Rockford; and ${ }^{N}$ \\ $\ddagger$ Division of Genetics, Department of Pediatrics, Evanston Hospital, Evanston, Illinois, USA.
}

SUMmARY A six month old girl with developmental delay and dysmorphic features was found to have a translocation involving $2 \mathrm{p}$ and $5 q$ as well as a deletion of band $5 q 21$.

Received for publication 6 April 1987

Revised version accepted for publication 7 August 1987.
Acquired interstitial deletion $5 q$ of bone marrowco

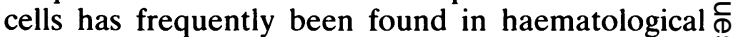
disorders. ${ }^{1}$ Constitutional interstitial deletion of $5 \mathrm{q} \stackrel{\text { ? }}{+}$ is, however, relatively rare. To our knowledge, $\urcorner$ there have been only 10 previous published cases of $\stackrel{P}{P}$ interstitial deletion $5 \mathrm{q} .{ }^{2-10}$ We report here a child $\stackrel{\odot}{\odot}$ with coloboma of the right eye, dysmorphic facial $\stackrel{\mathbb{Q}}{\Omega}$ 